\title{
Impact of Time Interval between Index Event and Stenting on Periprocedural Risk in Patients with Symptomatic Carotid Stenosis
}

\author{
Wonsuck Han, ${ }^{1}$ Gyojun Hwang, ${ }^{1}$ Sung Han Oh, Jong Joo Lee, Mi Kyung Kim, ${ }^{1}$ Bong Sub Chung, ${ }^{2}$ Jong Kook Rhim, ${ }^{3}$ \\ Seung Hun Sheen, ${ }^{4}$ Taehyung $\mathrm{Kim}^{5}$ \\ Department of Neurosurgery, Bundang Jesaeng General Hospital, Seongnam, Korea \\ Department of Neurosurgery, ${ }^{2}$ Anyang Sam Hospital, Anyang, Korea \\ Department of Neurosurgery, Jeju National University Hospital, Jeju, Korea \\ Department of Neurosurgery, 4 Bundang CHA Medical Center, CHA University, Seongnam, Korea \\ Department of Neurosurgery, ${ }^{5}$ Pyeongtaek St. Mary's Hospital, Pyeongtaek, Korea
}

Objective : The purpose of this study was to evaluate the impact of time interval between index event and stenting on the periprocedural risk of stenting for symptomatic carotid stenosis and to determine the optimal timing of stenting.

Methods : This retrospective study included 491 (322 symptomatic [65.6\%] and 169 asymptomatic [34.4\%]) patients undergoing carotid stenting. The symptomatic patients were categorized into Day $0-3,4-7,8-10,11-14,15-21$, and $>21$ groups according to the time interval between index event and stenting. Periprocedural ( $\leq 30$ days) risk for clinical (any neurological deterioration) and radiological (new infarction on postprocedural diffusion-weighted imaging) events of stenting in each time interval versus asymptomatic stenosis was calculated with logistic regression analysis adjusted for confounders, and provided as odds ratio (OR) and 95\% confidence interval (Cl).

Results : Overall clinical event rate (4.3\%) of stenting for symptomatic carotid stenosis was higher than that for asymptomatic stenosis (1.2\%; OR, 3.979 [95\% Cl, 1.093-14.489]; $p=0.036)$. Stenting in Day 0-3 (13.2\%; OR, 10.997 [95\% Cl, 2.333-51.826]; $p=0.002)$ and Day 4-7 (8.3\%; OR, 6.775 [95\% Cl, 1.382-33.227]; $p=0.018)$ was associated with high risk for clinical events. However, the clinical event rates in stenting after 7 days from index event (Day 8-10, 1.8\%; Day 11-14, 2.5\%; Day 15-21, 0\%; Day >21, 2.9\%) were not different from that in stenting for asymptomatic stenosis. Overall radiological event rate (55.6\%) in symptomatic stenosis was also higher than that in asymptomatic stenosis $(35.5 \%$; OR, 2.274 [95\% Cl, 1.553-3.352]; $p<0.001)$. The high risk for radiological events was maintained in all time intervals (Day 0-3 : 55.3\%; OR, 2.224 [95\% Cl, 1.103-4.627]; $p=0.026$; Day 4-7 : 58.3\%; OR, 2.543 [95\% Cl, 1.329-4.949]; $p=0.005$; Day 8-10 : 53.6\%; OR, 2.096 [95\% Cl, 1.138-3.889]; $p=0.018$; Day 11-14 : 57.5\%; OR, 2.458 [95\% Cl, 1.225-5.021]; $p=0.012$; Day 15-21 : 55.6\%; OR, 2.271 [95\% Cl, 1.099-4.764]; $p=0.028$; Day >21 : 54.8\%; OR, 2.203 [95\% Cl, 1.342-3.641]; $p=0.002$ ).

Conclusion : This study showed that as stenting was delayed, the periprocedural risk for clinical events decreased. The clinical event risk was high only in stenting within 7 days and comparable with that for asymptomatic stenosis in stenting after 7 days from index event, although the radiological event risk was not affected by stenting timing. Therefore, our results suggest that delayed stenting after 7 days from symptom onset is a safe strategy for symptomatic stenosis.

Key Words : Carotid stenosis · Stents · Cerebral infarction.

\footnotetext{
- Received : April 13, 2020 •Revised : May 31, 2020 •Accepted : June 22, 2020

- Address for reprints : Gyojun Hwang

Department of Neurosurgery, Bundang Jesaeng General Hospital, 20 Seohyeon-ro 180beon-gil, Bundang-gu, Seongnam 13590, Korea

Tel : +82-31-799-0280, Fax : +82-31-799-0929, E-mail : hwang.gyojun.md@gmail.com, ORCID : https://orcid.org/0000-0002-7405-0487
}

This is an Open Access article distributed under the terms of the Creative Commons Attribution Non-Commercial License (http://creativecommons.org/licenses/by-nc/4.0) which permits unrestricted non-commercial use, distribution, and reproduction in any medium, provided the original work is properly cited. 


\section{INTRODUCTION}

There is increasing evidence that carotid revascularization for symptomatic carotid stenosis confers maximum benefit if performed within 14 days from symptom onset ${ }^{1,11,16,17)}$. Metaanalyses, including large randomized studies, showed that early stenting in patients with symptomatic carotid stenosis had higher periprocedural (within 30 days) stroke and death rates than endarterectomy ${ }^{13,14)}$. Based on these results, endarterectomy is recommended for patients who need early carotid revascularization rather than stenting ${ }^{11,12)}$. In real practice, however, stenting is frequently performed for symptomatic carotid stenosis according to surgeon's preference or institutional policy. Guidelines also accept stenting as an alternative to endarterectomy if it has an acceptable rate of periprocedural stroke or death ${ }^{11)}$.

Although the literature shows conflicting data on carotid stenting in early period, we found that periprocedural event rates gradually decreased as stenting was delayed from symptom onset ${ }^{2,5,6,19-23)}$. Several studies reported periprocedural stroke or death rate of $1-4 \%$ in delayed stenting after 1 or 2 weeks from neurological index event ${ }^{6,20-22)}$, which was comparable with that in stenting for asymptomatic stenosis ${ }^{3,15,18)}$. Therefore, we assumed that there would be an early period with high procedural risk, and if delayed after this period, stenting for symptomatic carotid stenosis can be safely performed. The purpose of this study was to analyze the periprocedural event rates of stenting for symptomatic versus asymptomatic carotid stenosis stratified for delay from neurological index event to stenting, and to determine the optimal timing of stenting.

\section{MATERIALS AND METHODS}

\section{Patients}

This study was approved by the Institutional Review Board of Bundang Jesaeng General Hospital (DMC 2020-04-001). The requirement to obtain written informed consent to participate in this study was waived. We retrieved basic data on patients from a carotid stenting registry obtained in our institute between January 2000 and February 2020. This study included all consecutive patients who underwent stenting for asymptomatic or symptomatic (amaurosis fugax, transient ischemic attack [TIA], or ischemic stroke within previous 6 months) carotid stenosis. We excluded patients with 1) moderate or severe neurological deficit (National Institutes of Health Stroke Scale [NIHSS] score $>5$ ); 2) tandem occlusion in the intracranial large arteries; 3) large territorial infarction on diffusion-weighted imaging (DWI); 4) non-atherosclerotic stenosis including vasculitis or dissection; or 5) poor functional status before admission (modified Rankin scale score $\geq 2$ ). Among the 544 patients reviewed, 53 were excluded according to the inclusion and exclusion criteria, and 491 were finally enrolled in this study.

The guidelines of the Korean Health Insurance Review and Assessment Service were followed for selecting patients who needed carotid stenting : 1 ) asymptomatic $\geq 70 \%$ carotid stenosis with apparent perfusion defect (before August 2019, asymptomatic $\geq 80 \%$ carotid stenosis) and 2) symptomatic (onset within 6 months) $\geq 50 \%$ carotid stenosis (before August 2019 , symptomatic $\geq 70 \%$ or $50-69 \%$ carotid stenosis with high surgical risk or special conditions including ulcerative plaque or restenosis after endarterectomy).

\section{Carotid stenting procedure}

Dual antiplatelet and high-dose statin therapy was administrated in all patients. According to stenting protocol, daily dose of aspirin (100 mg), clopidogrel (75 mg), and atorvastatin (40 or $80 \mathrm{mg}$ ) were initiated at least 5 days before procedure. However, for patients with symptomatic stenosis who were directly admitted via emergency room, antiplatelet therapy began with loading dose of aspirin (300 mg) and clopidogrel (300 mg).

All stenting procedure was performed under local anesthesia. Transcutaneous temporary cardiac pacing was applied and set to capture a heart rate $<40$ beats/min. Systemic heparization was administrated after placement of the femoral sheath (target level of activated clotting time, 250-300 seconds). A guiding catheter was placed in the common carotid artery. After embolic protection device was deployed, balloon angioplasty was performed and then a stent was placed in the stenosis. The embolic protection devices were used in all patients and included Emboshield NAV6 (Abbott, Chicago, IL, USA), Spider FX (Medtronic, Minneapolis, MN, USA), and FilterWire EZ (Boston Scientific, Marlborough, MA, USA). Sterling (Boston Scientific), Submarine (Medtronic), or Aviator (Cordis, Santa Clara, CA, USA) balloon catheter was used for balloon angio- 
plasty. The stents used for the procedure included Wallstent (closed-cell type; Boston Scientific), Protégé (open-cell type; Medtronic), Acculink (open-cell type; Abbott), Precise (opencell type; Cordis), and Cristallo (hybrid type; Medtronic) stents. Post ballooning was performed to ensure the residual stenosis of $<30 \%$. During the procedure, patients were carefully monitored for blood pressure by arterial line, electrocardiography, and neurological status, and proper management was employed to maintain stable hemodynamic status (systolic blood pressure $100-140 \mathrm{mmHg}$ and heart rate $50-100$ beats/min). After the procedure, the patients were admitted to the intensive care unit, and the monitoring was continued.

DWI was obtained within 3 days before and 1 day after the procedure. Perfusion-weighted imaging (PWI) was added in post magnetic resonance imaging study for the patients who had neurological deterioration after the procedure. Dual antiplatelet therapy was maintained until 1 year, and thereafter switched to monotherapy. Dose and component of statin were adjusted according to follow-up laboratory and radiological findings.

\section{Outcomes}

The primary outcome for the measure of periprocedural risk was clinical events, which were defined as neurological deterioration (an increase of $\geq 1$ point in motor power or an increase of $\geq 2$ points in the total NIHSS score caused by stroke, hyperperfusion syndrome, intracranial hemorrhage, or any procedural complications) ${ }^{4,7-10,24)}$ or any death within 30 days of carotid stenting. Stroke was defined as TIA or ischemic stroke with evidence of new infarction on DWI, which resulted in new neurological deficits that occurred in the vascular territory consistent with stented carotid artery. Hyperperfusion syndrome was confirmed when neurological deterioration with corresponding findings on PWI occurred after stenting without evidence of new infarction on DWI.

Secondary outcome was radiological events, which were defined as the presence of any new embolic lesions on post-procedure DWI that were not present before stenting. This was included as surrogate endpoint for the clinical events in this study.

All demographic, clinical, and radiological data of patients were collected by review of medical records and imaging studies stored in PACS system ( $\pi$ View Star; INFINITT Healthcare, Seoul, Korea) in addition to basic data retrieved from our carotid stenting registry. The primary and secondary outcomes were adjudicated by two independent reviewers and discrepancies were solved by consensus.

\section{Statistical analysis}

The t-test was used for continuous variables, and the chisquare test or Fisher's exact test was used for nominal factors in comparisons of baseline characteristics between patients with symptomatic and asymptomatic carotid stenoses. The patients with symptomatic stenosis were categorized into Day $0-3,4-7,8-10,11-14,15-21$, and $>21$ groups according to the time interval between index event and stenting. In order to calculate the adjusted odds ratio (OR) and 95\% confidence interval (CI) for the periprocedural risk of stenting in each time interval versus asymptomatic carotid stenosis, the primary and secondary outcomes were compared with binary logistic regression analysis, adjusted for confounders. Factors showing a baseline group difference at a $p$-value $<0.2$ with clinical relevance were included as fixed effect in the logistic model, in addition to traditional risk factors for periprocedural events in carotid intervention, such as age, initial stenosis, ulceration in the lesion, stent type, and post-ballooning. The year of stenting and surgeon were also included in the model as random effects to account for their confounding and clustering effects. As exploratory analysis, the probability of the primary and secondary outcomes at specific stenting timing in patients with symptomatic carotid stenosis was estimated with logistic regression model including time interval as a continuous variable. The penalized likelihood estimation method was used in logistic regression which needed to deal with rare events.

Period with high periprocedural risk was determined as the time interval where 95\% CI of the estimated risk for the primary outcome was over reference level. Because the principal analysis in this study was the primary outcome comparison, no adjustment for multiplicity was considered in the secondary outcome comparison and exploratory analysis. Statistical analyses were conducted using SAS Studio (version 3.8; SAS Institute Inc., Cary, NC, USA). Statistical significance was accepted for $p$-value $<0.05$.

\section{RESULTS}

Baseline characteristics of 491 patients including 322 
Table 1. Baseline characteristics of patients with symptomatic and asymptomatic carotid stenoses

\begin{tabular}{|c|c|c|c|}
\hline & $\begin{array}{c}\text { Symptomatic } \\
(n=322 \\
65.6 \%)\end{array}$ & $\begin{array}{c}\text { Asymptomatic } \\
\qquad \begin{array}{c}(n=169 \\
34.4 \%)\end{array}\end{array}$ & $p$-value \\
\hline Male & $256(79.5)$ & $141(83.4)$ & 0.335 \\
\hline Age (years) & $70.2 \pm 8.9$ & $71.8 \pm 7.9$ & 0.046 \\
\hline \multicolumn{4}{|l|}{ Symptom type } \\
\hline $\mathrm{TIA}$ & $45(14.0)$ & $0(0.0)$ & - \\
\hline Infarction & $277(86.0)$ & $0(0.0)$ & \\
\hline \multicolumn{4}{|l|}{ Past history } \\
\hline Hypertension & $194(60.3)$ & $109(64.5)$ & 0.380 \\
\hline Diabetes mellitus & $124(38.5)$ & $60(35.5)$ & 0.556 \\
\hline Coronary heart disease & $72(22.4)$ & $40(23.7)$ & 0.736 \\
\hline Atrial fibrillation & $21(6.5)$ & $8(4.7)$ & 0.547 \\
\hline Ischemic stroke & $66(20.5)$ & $32(18.9)$ & 0.723 \\
\hline Hemorrhagic stroke & $25(7.8)$ & $18(10.7)$ & 0.314 \\
\hline \multicolumn{4}{|l|}{ Smoking } \\
\hline Current & $98(30.4)$ & $28(16.6)$ & 0.001 \\
\hline Former & 108 (33.6) & $57(33.7)$ & \\
\hline Never & $116(36.0)$ & $84(49.7)$ & \\
\hline \multicolumn{4}{|l|}{$\begin{array}{l}\text { Medication before } \\
\text { admission }\end{array}$} \\
\hline Antiplatelet drugs & $92(28.6)$ & $55(32.5)$ & 0.407 \\
\hline Anticoagulants & $21(6.5)$ & $7(4.1)$ & 0.314 \\
\hline Statin & $61(18.9)$ & $40(23.7)$ & 0.240 \\
\hline \multicolumn{4}{|l|}{ Laboratory data } \\
\hline Hemoglobin (g/dL) & $13.0 \pm 1.8$ & $12.6 \pm 1.9$ & 0.007 \\
\hline Hematocrit, (\%) & $39.8 \pm 12.3$ & $37.1 \pm 5.7$ & 0.007 \\
\hline Platelet $\left(\times 10^{3} / \mu \mathrm{L}\right)$ & $226.0 \pm 57.8$ & $209.5 \pm 54.4$ & 0.002 \\
\hline Prothrombin time (INR) & $1.06 \pm 0.13$ & $1.08 \pm 0.18$ & 0.202 \\
\hline $\begin{array}{l}\text { Partial thromboplatin } \\
\text { time (seconds) }\end{array}$ & $34.4 \pm 12.9$ & $33.4 \pm 9.6$ & 0.350 \\
\hline Glucose (mg/dL) & $122.3 \pm 37.4$ & $126.0 \pm 41.6$ & 0.278 \\
\hline Total cholesterol (mg/dL) & $159.1 \pm 36.9$ & $156.9 \pm 41.4$ & 0.722 \\
\hline Triglyceride (mg/dL) & $124.8 \pm 57.1$ & $129.7 \pm 83.2$ & 0.381 \\
\hline $\begin{array}{l}\text { Low-density lipoprotein } \\
\text { (mg/dL) }\end{array}$ & $94.6 \pm 31.4$ & $91.4 \pm 35.3$ & 0.209 \\
\hline $\begin{array}{l}\text { High-density lipoprotein } \\
(\mathrm{mg} / \mathrm{dL})\end{array}$ & $46.4 \pm 19.9$ & $48.3 \pm 13.8$ & 0.512 \\
\hline
\end{tabular}

$(65.6 \%)$ with symptomatic carotid stenosis are summarized in Table 1. Age $(p=0.046)$ and current smoker $(p=0.001)$ were lower and more frequent in the patients with symptomatic ca-
Table 1. Continued

\begin{tabular}{|c|c|c|c|}
\hline & $\begin{array}{c}\text { Symptomatic } \\
(n=322, \\
65.6 \%)\end{array}$ & $\begin{array}{c}\text { Asymptomatic } \\
\text { (n=169, } \\
34.4 \%)\end{array}$ & $p$-value \\
\hline \multicolumn{4}{|l|}{ Procedural data } \\
\hline \multicolumn{4}{|l|}{ Lesion side } \\
\hline Left & $171(53.1)$ & $100(59.2)$ & 0.215 \\
\hline Right & $151(46.9)$ & 69 (40.8) & \\
\hline Initial stenosis* (\%) & $78.6 \pm 12.1$ & $79.2 \pm 12.1$ & 0.611 \\
\hline Ulceration in the lesion & $193(59.9)$ & $92(54.4)$ & 0.249 \\
\hline \multicolumn{4}{|l|}{ Aortic arch type } \\
\hline Type I & 97 (30.1) & $49(29.0)$ & 0.358 \\
\hline Type ॥ & $104(32.3)$ & $65(38.5)$ & \\
\hline Type III & $121(37.6)$ & $55(52.5)$ & \\
\hline Aortic arch atheroma & $203(63.0)$ & $104(61.5)$ & 0.769 \\
\hline Aortic arch ulceration & $75(23.3)$ & $34(20.1)$ & 0.493 \\
\hline \multicolumn{4}{|l|}{$\begin{array}{l}\text { Embolic protection } \\
\text { device }\end{array}$} \\
\hline Emboshield & $92(28.6)$ & $40(23.7)$ & 0.430 \\
\hline FilterWire & $18(5.6)$ & $8(4.7)$ & \\
\hline Spider & $212(65.8)$ & $121(71.6)$ & \\
\hline Balloon diameter (mm) & $4.1 \pm 0.6$ & $4.2 \pm 0.6$ & 0.036 \\
\hline $3 \mathrm{~mm}$ & $29(9.0)$ & $12(7.1)$ & 0.094 \\
\hline $4 \mathrm{~mm}$ & $299(71.1)$ & $109(64.5)$ & \\
\hline $5-6 \mathrm{~mm}$ & 64 (19.9) & $48(28.4)$ & \\
\hline \multicolumn{4}{|l|}{ Stent type } \\
\hline Closed-cell & $16(5.0)$ & $20(11.8)$ & 0.006 \\
\hline Open-cell & $266(82.6)$ & $121(71.6)$ & \\
\hline Hybrid & $40(12.4)$ & $28(16.6)$ & \\
\hline Post-ballooning & $120(37.3)$ & $67(39.6)$ & 0.626 \\
\hline $\begin{array}{l}\text { Residual stenosis* } \\
\quad(\mathrm{mm})\end{array}$ & $16.9 \pm 10.6$ & $14.2 \pm 11.1$ & 0.009 \\
\hline
\end{tabular}

Values are presented as mean \pm standard deviation or number (\%). *Stenosis was measured using the North American Symptomatic Carotid Endarterectomy Trial (NASCET) method. TIA : transient ischemic attack

rotid stenosis than those with asymptomatic stenosis. In laboratory data, hemoglobin ( $p=0.007$ ), hematocrit ( $p=0.007$ ), and platelet count $(p=0.002)$ were higher in patients with symptom- 
atic stenosis. In procedural data, balloon diameter $(p=0.036)$, stent type $(p=0.006)$, and residual stenosis $(p=0.009)$ showed significant group difference. Therefore, theses variables were added as covariates in the outcome analysis.

Clinical events developed in 16 (3.3\%; 14 [2.9\%] in symptomatic and two [0.4\%] in asymptomatic) patients within 1 month of carotid stenting, and presented with stroke in 14 (2.9\%) and hyperperfusion syndrome in two (0.4\%). Neither intracranial hemorrhage nor mortality was observed. At 1 month after stenting, all patients with clinical event showed full recovery or improvement compared with initial neurological status at admission. The radiological events were observed in 239 (48.7\%; 179 [36.5\%] in symptomatic and 60 [12.2\%] in asymptomatic) cases on DWI obtained after procedure.

The overall clinical event rate of stenting for symptomatic carotid stenosis (14/322 [4.3\%]) was significantly higher than that for asymptomatic stenosis (2/169 [1.2\%]; OR, 3.979 [95\% CI, 1.093-14.489]; $p=0.036$; Table 2). In particular, stenting in Day 0-3 (5/38 [13.2\%]; OR, 10.997 [95\% CI, 2.333-51.826]; $p=0.002)$ and Day 4-7 (4/48 [8.3\%]; OR, 6.775 [95\% CI, 1.382-
33.227]; $p=0.018$ ) was associated with high risk for the clinical events, compared with stenting for asymptomatic stenosis. However, the clinical event rates in stenting after 7 days from index event were not different from that in stenting for asymptomatic stenosis (Day 8-10 : 1/56 [1.8\%]; OR, 1.811 [95\% CI, 0.231-14.216]; $p=0.572$; Day 11-14 : 1/40 [2.5\%]; OR, 2.544 [95\% CI, 0.320-20.205]; $p=0.377$; Day 15-21 : 0/36 [0\%]; OR, 2.831 [95\% CI, 0.355-22.583]; $p=0.326$; Day $>21$ : 3/104 [2.9\%]; OR, 2.310 [95\% CI, 0.455-12.003]; $p=0.319$ ).

Overall radiological event rate was also significantly higher in stenting for symptomatic stenosis (179/322 [55.6\%]) than that for asymptomatic stenosis (60/169 [35.5\%]; OR, 2.274 [95\% CI, 1.553-3.352]; $p<0.001$ ). Even when this comparison was stratified by given time intervals, the high risk of radiological events in stenting for symptomatic stenosis was maintained (Day 0-3 : 21/38 [55.3\%]; OR, 2.224 [95\% CI, 1.1034.627]; $p=0.026$; Day 4-7 : 28/48 [58.3\%]; OR, 2.543 [95\% CI, 1.329-4.949]; $p=0.005$; Day 8-10 : 30/56 [53.6\%]; OR, 2.096 [95\% CI, 1.138-3.889]; $p=0.018$; Day 11-14 : 23/40 [57.5\%]; OR, 2.458 [95\% CI, 1.225-5.021]; $p=0.012$; Day $15-21: 20 / 36$

Table 2. Primary and secondary outcomes

\begin{tabular}{|c|c|c|c|c|}
\hline & Event & Odds ratio* & 95\% confidence interval & $p$-value \\
\hline \multicolumn{5}{|l|}{ Clinical event } \\
\hline Asymptomatic & $2 / 169(1.2)$ & Reference & & \\
\hline Symptomatic & $14 / 322(4.3)$ & 3.979 & $1.093-14.489$ & 0.036 \\
\hline Day 0-3 & $5 / 38(13.2)$ & 10.997 & $2.333-51.826$ & 0.002 \\
\hline Day 4-7 & $4 / 48(8.3)$ & 6.775 & $1.382-33.227$ & 0.018 \\
\hline Day 8-10 & $1 / 56(1.8)$ & 1.811 & $0.231-14.216$ & 0.572 \\
\hline Day 11-14 & $1 / 40(2.5)$ & 2.544 & $0.320-20.205$ & 0.377 \\
\hline Day $15-21$ & $0 / 36(0.0)$ & 2.831 & $0.355-22.583$ & 0.326 \\
\hline Day $>21$ & 3/104 (2.9) & 2.31 & $0.455-12.003$ & 0.319 \\
\hline \multicolumn{5}{|l|}{ Radiological event } \\
\hline Asymptomatic & $60 / 169(35.5)$ & Reference & & \\
\hline Symptomatic & $179 / 322(55.6)$ & 2.274 & $1.553-3.352$ & $<0.001$ \\
\hline Day 0-3 & 21/38 (55.3) & 2.244 & $1.103-4.627$ & 0.026 \\
\hline Day 4-7 & 28/48 (58.3) & 2.543 & $1.329-4.949$ & 0.005 \\
\hline Day 8-10 & $30 / 56(53.6)$ & 2.096 & $1.138-3.889$ & 0.018 \\
\hline Day 11-14 & $23 / 40(57.5)$ & 2.458 & $1.225-5.021$ & 0.012 \\
\hline Day $15-21$ & 20/36 (55.6) & 2.271 & $1.099-4.764$ & 0.028 \\
\hline Day $>21$ & $57 / 104(54.8)$ & 2.203 & $1.342-3.641$ & 0.002 \\
\hline
\end{tabular}

*Each outcome comparison was adjusted for age, smoking status, hemoglobin, platelet count, initial and residual stenoses, ulceration in the lesion, balloon diameter, stent type, year of stenting, and surgeon 
[55.6\%]; OR, 2.271 [95\% CI, 1.099-4.764]; $p=0.028$; Day $>21$ : 57/104 [54.8\%]; OR, 2.203 [95\% CI, 1.342-3.641]; $p=0.002$ ).

Fig. 1 showed the estimated OR curves. As the time interval between index event and stenting increased, the OR for clinical events gradually decreased. Therefore, its 95\% CI was found to be over the reference line $(\mathrm{OR}, 1)$ only in Day $0-3$ and 4-7. However, the OR for radiological events showed little time-course change, and the lower margin of 95\% CI of OR for radiological events was over the reference line in all time interval groups. The probabilities of clinical and radiological events were estimated with logistic regression analysis, and these curves are shown in Fig. 2. When the overall probability of given events in stenting for symptomatic stenosis was selected as reference, the lower margin of $95 \%$ CI of probability for clinical event was found to exceed the reference line (overall probability of clinical events, 0.043 [log-odds, -3.109]) only within 7 days from index event (probability at Day 7, 0.063 [95\% CI, 0.042-0.093]). The reference line for radiological events $(0.556$ [log-odds, 0.225$])$ was within 95\% CI of probability through all time periods.

\section{DISCUSSION}

This study showed that the clinical event risk of stenting for symptomatic versus asymptomatic carotid stenosis decreased as stenting was delayed. The clinical event rate in symptomatic stenosis was found to be high only within 7 days from index
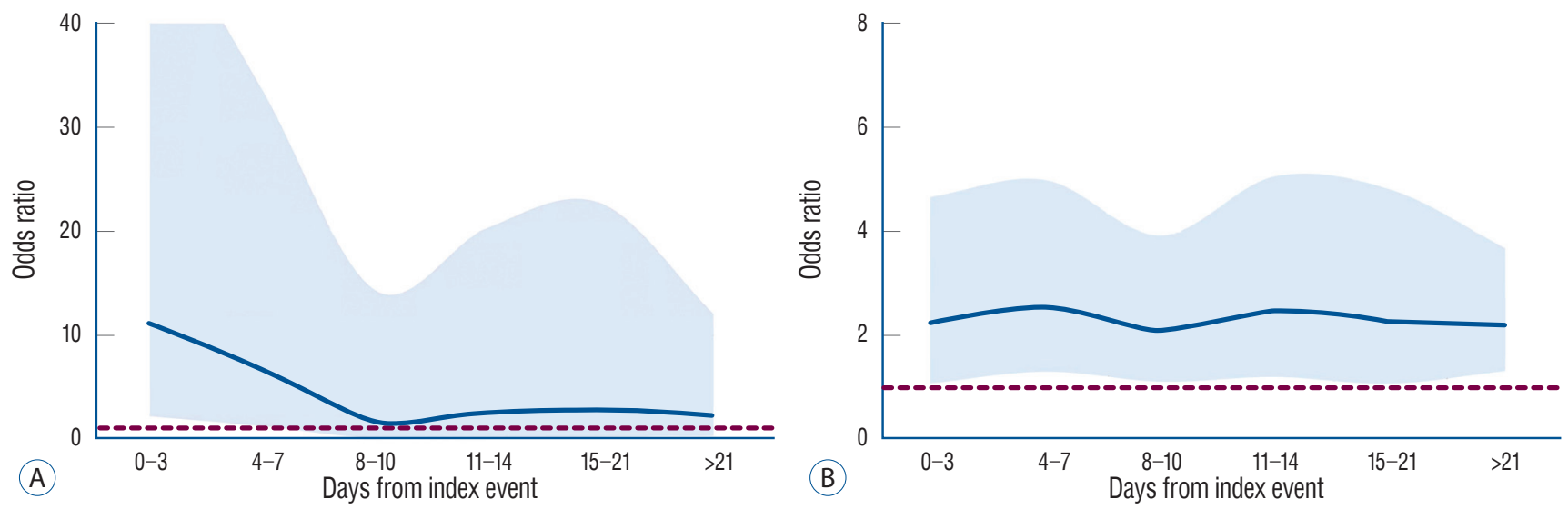

Fig. 1. Estimated odds ratio curves with $95 \%$ confidence interval for the clinical (A) and radiological (B) events in stenting for symptomatic versus asymptomatic carotid stenosis. References (dotted line) indicates odds ratio of 1.
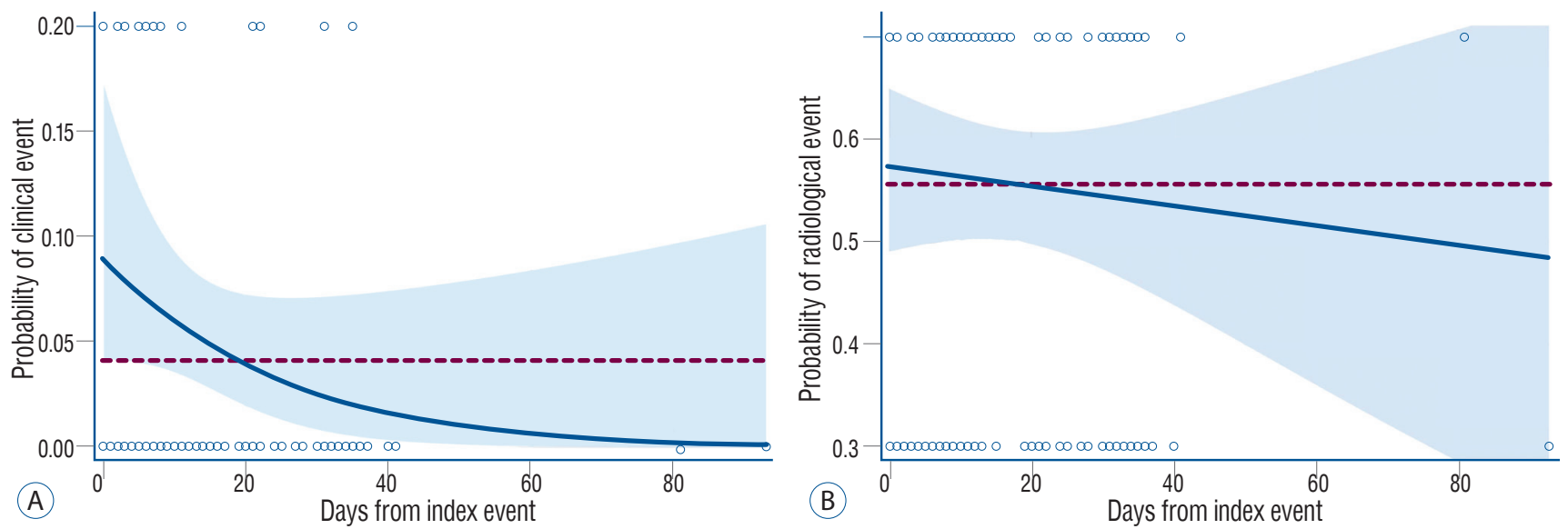

Fig. 2. Estimated probability curves with $95 \%$ confidence interval for the clinical (A) and radiological (B) events in stenting for symptomatic carotid stenosis. References (dotted line) indicates the overall probability of given events ( 0.043 for clinical and 0.556 for radiological events). 
event, and not different from that in asymptomatic stenosis thereafter. However, the new embolic infarction frequently developed in stenting for symptomatic stenosis, and the radiological event risk of stenting for symptomatic versus asymptomatic stenosis was not affected by time interval between index event and stenting.

Carotid stenting for symptomatic stenosis has a high rate of periprocedural stroke or death, which was reported to be up to $26.1 \%{ }^{2,5,6,19-23)}$. However, our literature review found that the periprocedural risk decreased in delayed stenting ${ }^{6,20-22)}$, which supports our finding. In real practice, because carotid stenosis with moderate or severe neurological symptoms is treated by urgent endovascular treatment within 8 hours of symptom onset according to acute stroke protocol, delayed stenting is usually applied for patients with mild symptoms. Considering the current practice, we included only patients with TIA or mild symptoms (NIHSS score $\leq 5$ ) in this analysis, when planning the present study. In a similar manner, when we limited our literature review to studies in which a majority of participants were patients with TIA or mild neurological symptoms, the reported rate of periprocedural event in the delayed stenting decreased further to about $2 \%(0.8-4.7)$, which was not high compared with that in large randomized trials for stenting for asymptomatic stenosis ${ }^{3,15,18)}$. Therefore, the results in our study and literature review suggest that stenting for symptomatic carotid stenosis can have periprocedural risk comparable with asymptomatic stenosis when it is performed in delayed fashion in patients with TIA or mid neurological symptoms.

The present study showed that early stenting within 7 days from index event was associated with high clinical event risk compared with stenting for asymptomatic stenosis. Additionally, the estimated probability of clinical events in early stenting was also found to be higher than its overall probability. Similar to our study, a national-wide cohort study that evaluated the periprocedural risk for stroke and death in stenting for symptomatic carotid stenosis stratified by time interval between index event and stenting showed higher stroke or death risk in early stenting within 7 days than overall event risk in symptomatic stenosis ${ }^{6}$. In theory, the high clinical event risk in early stenting can be explained by high vulnerability of plaque and limited time to achieve full effect of antiplatelet and statin therapy. Therefore, based on the currently available data, if stenting is chosen as treatment option for symptomatic carotid stenosis, we recommend that stenting needs to be delayed to 7 days from symptom onset.

Radiological events that indicate new embolic infarction following stenting were included as surrogate endpoints for the clinical events in this study. We found that radiological events occurred more frequently in stenting for symptomatic carotid stenosis, and its risk did not decrease even when stenting was delayed. These findings indicate that plaque in symptomatic stenosis is vulnerable to procedure and not easily resolved with time. However, we did not find any clinical impact of radiological events on prognosis in the periprocedural period. Therefore, future research needs to evaluate the long-term effect of radiological events.

The present study is limited by its retrospective nature, and biases for deciding stenting timing. Second, data were based on medical records and images. Thus, several important pieces of information could be omitted. In particular, mild clinical events that occurred between discharge and 1-month outpatient follow-up could not be recorded. Therefore, the event rate may have been underestimated. Third, this study included the overall number of patients sufficient for usual risk analysis, but because the patients were divided into several groups according to time interval, the small number of patients in each time interval group led to wide 95\% CI. Finally, carotid stenting in this study was performed by several surgeons over a period of 20 years. Although we included these factors as random effects in the outcome analysis to account for this issue statistically, it is apparent that this issue could not be perfectly solved.

\section{CONCLUSION}

Stenting in patients with symptomatic carotid stenosis yielded high rates of periprocedural clinical and radiological events, but the clinical event risk gradually decreased as stenting was delayed. This study including patients with mild neurological symptoms showed that the clinical event risk was high only in stenting within 7 days, and comparable with that for asymptomatic patients in stenting after 7 days from index event. Therefore, our results suggest that delayed carotid stenting after 7 days from symptom onset is a safe strategy for patients with mild symptoms. 


\section{CONFLICT OF INTEREST}

There is no conflict of interest to disclose.

\section{INFORMED CONSENT}

This type of study does not require informed consent.

\section{AUTHOR CONTRIBUTIONS}

\author{
Conceptualization : $\mathrm{GH}$ \\ Data curation : GH, WH \\ Formal analysis : $\mathrm{GH}$ \\ Methodology : GH \\ Project administration : GH \\ Visualization : GH \\ Writing - original draft : $\mathrm{GH}, \mathrm{WH}$ \\ Writing - review \& editing: GH, WH, SHO, JJL, MKK, \\ BSC, JKR, SHS, TK
}

\section{ORCID}

$\begin{array}{ll}\text { Wonsuck Han } & \text { https://orcid.org/0000-0003-2946-5605 } \\ \text { Gyojun Hwang } & \text { https://orcid.org/0000-0002-7405-0487 } \\ \text { Sung Han Oh } & \text { https://orcid.org/0000-0001-9037-7386 } \\ \text { Jong Joo Lee } & \text { https://orcid.org/0000-0003-0905-0330 } \\ \text { Mi Kyung Kim } & \text { https://orcid.org/0000-0002-8824-0505 } \\ \text { Bong Sub Chung } & \text { https://orcid.org/0000-0002-6327-272X } \\ \text { Jong Kook Rhim } & \text { https://orcid.org/0000-0003-2538-8374 } \\ \text { Seung Hun Sheen } & \text { https://orcid.org/0000-0002-0454-8810 } \\ \text { Taehyung Kim } & \text { https://orcid.org/0000-0001-8796-8628 }\end{array}$

\section{References}

1. Brott TG, Halperin JL, Abbara S, Bacharach JM, Barr JD, Bush RL, et al. 2011 ASA/ACCF/AHA/AANN/AANS/ACR/ASNR/CNS/SAIP/SCAI/SIR/ SNIS/SVM/SVS guideline on the management of patients with extracranial carotid and vertebral artery disease. Stroke 42 : e464-e540, 2011

2. de Castro-Afonso LH, Nakiri GS, Monsignore LM, dos Santos AC, Leite JP, Fábio SR, et al. : Early versus late carotid artery stenting for symptomatic carotid stenosis. J Neuroradiol 42 : 169-175, 2015
3. Eckstein $H H$, Reiff $T$, Ringleb $P$, Jansen $O$, Mansmann $U$, Hacke W, et al. : SPACE-2: a missed opportunity to compare carotid endarterectomy, carotid stenting, and best medical treatment in patients with asymptomatic carotid stenoses. Eur J Vasc Endovasc Surg 51 : 761-765, 2016

4. Geng HH, Wang Q, Li B, Cui BB, Jin YP, Fu RL, et al. : Early neurological deterioration during the acute phase as a predictor of long-term outcome after first-ever ischemic stroke. Medicine (Baltimore) 96 : e9068, 2017

5. Gröschel K, Knauth M, Ernemann U, Pilgram SM, Schnaudigel S, Kastrup A : Early treatment after a symptomatic event is not associated with an increased risk of stroke in patients undergoing carotid stenting. Eur J Neurol $15: 2-5,2008$

6. Jonsson M, Gillgren P, Wanhainen A, Acosta S, Lindström D : Periprocedural risk with urgent carotid artery stenting: a population based swedvasc study. Eur J Vasc Endovasc Surg 49 : 506-512, 2015

7. Kim JT, Heo SH, Yoon W, Choi KH, Park MS, Saver JL, et al. : Clinical outcomes of patients with acute minor stroke receiving rescue IA therapy following early neurological deterioration. J Neurointerv Surg 8 : 461-465, 2016

8. Kim YD, Song D, Kim EH, Lee KJ, Lee HS, Nam CM, et al. : Long-term mortality according to the characteristics of early neurological deterioration in ischemic stroke patients. Yonsei Med J 55 : 669-675, 2014

9. Kwon HM, Lee YS, Bae HJ, Kang DW : Homocysteine as a predictor of early neurological deterioration in acute ischemic stroke. Stroke 45 : 871-873, 2014

10. Kwon HM, Lim JS, Park HK, Lee YS : Hypertriglyceridemia as a possible predictor of early neurological deterioration in acute lacunar stroke. J Neurol Sci 309 : 128-130, 2011

11. Naylor AR, Ricco JB, de Borst GJ, Debus S, de Haro J, Halliday A, et al. : Editor's Choice - management of atherosclerotic carotid and vertebral artery disease: 2017 clinical practice guidelines of the European Society for Vascular Surgery (ESVS). Eur J Vasc Endovasc Surg 55 : 3-81, 2018

12. Powers WJ, Rabinstein AA, Ackerson T, Adeoye OM, Bambakidis NC, Becker $\mathrm{K}$, et al. : Guidelines for the early management of patients with acute ischemic stroke: 2019 update to the 2018 guidelines for the early management of acute ischemic stroke: a guideline for healthcare professionals from the American Heart Association/American Stroke Association. Stroke 50 : e344-e418, 2019

13. Rantner B, Goebel G, Bonati LH, Ringleb PA, Mas JL, Fraedrich G, et al. : The risk of carotid artery stenting compared with carotid endarterectomy is greatest in patients treated within 7 days of symptoms. J Vasc Surg 57 : 619-626.e2; discussion 625-626, 2013

14. Rantner B, Kollerits B, Roubin GS, Ringleb PA, Jansen O, Howard G, et al. : Early endarterectomy carries a lower procedural risk than early stenting in patients with symptomatic stenosis of the internal carotid artery: results from 4 randomized controlled trials. Stroke 48 : 15801587, 2017

15. Rosenfield K, Matsumura JS, Chaturvedi S, Riles T, Ansel GM, Metzger $D C$, et al. : Randomized trial of stent versus surgery for asymptomatic carotid stenosis. N Engl J Med 374 : 1011-1020, 2016 
16. Rothwell PM, Eliasziw M, Gutnikov SA, Warlow CP, Barnett HJ : Sex difference in the effect of time from symptoms to surgery on benefit from carotid endarterectomy for transient ischemic attack and nondisabling stroke. Stroke 35 : 2855-2861, 2004

17. Rothwell PM, Eliasziw M, Gutnikov SA, Warlow CP, Barnett HJ; Carotid Endarterectomy Trialists Collaboration : Endarterectomy for symptomatic carotid stenosis in relation to clinical subgroups and timing of surgery. Lancet 363 : 915-924, 2004

18. Silver FL, Mackey A, Clark WM, Brooks W, Timaran CH, Chiu D, et al. : Safety of stenting and endarterectomy by symptomatic status in the Carotid Revascularization Endarterectomy Versus Stenting Trial (CREST). Stroke $42: 675-680,2011$

19. Song KS, Kwon OK, Hwang G, Bae HJ, Han MK, Kim BJ, et al. : Early carotid artery stenting for symptomatic carotid artery stenosis. Acta Neurochir (Wien) 157 : 1873-1878, 2015

20. Topakian R, Strasak AM, Sonnberger M, Haring HP, Nussbaumer K, Trenkler J, et al. : Timing of stenting of symptomatic carotid stenosis is predictive of 30-day outcome. Eur J Neurol 14 : 672-678, 2007
21. Tsantilas P, Kuehnl A, Kallmayer M, Knappich C, Schmid S, Breitkreuz T, et al. : Risk of stroke or death is associated with the timing of carotid artery stenting for symptomatic carotid stenosis: a secondary data analysis of the german statutory quality assurance database. J Am Heart Assoc 7 : e007983, 2018

22. Wach MM, Dumont TM, Mokin M, Kass-Hout T, Snyder KV, Hopkins $L N$, et al. : Early carotid angioplasty and stenting may offer non-inferior treatment for symptomatic cases of carotid artery stenosis. J Neurointerv Surg $6: 276-280,2014$

23. Yang NR, Jeon P, Kim B, Kim KH, Jo KI : Usefulness of early stenting for symptomatic extracranial carotid stenosis. World Neurosurg 96 : 334-339, 2016

24. Zhang $X$, Sun Z, Ding C, Tang Y, Jiang X, Xie Y, et al. : metabolic syndrome augments the risk of early neurological deterioration in acute ischemic stroke patients independent of inflammatory mediators: a hospital-based prospective study. Oxid Med Cell Longev 2016 : 8346301, 2016 